\title{
A Longitudinal Test of the Demand-Control Model Using Specific Job Demands and Specific Job Control
}

\author{
Jan de Jonge • Natasja van Vegchel • Akihito Shimazu • \\ Wilmar Schaufeli • Christian Dormann
}

Published online: 3 March 2010

(C) The Author(s) 2010. This article is published with open access at Springerlink.com

\begin{abstract}
Background Supportive studies of the demand-control (DC) model were more likely to measure specific demands combined with a corresponding aspect of control. Purpose A longitudinal test of Karasek's (Adm Sci Q. 24:285-308, 1) job strain hypothesis including specific measures of job demands and job control, and both selfreport and objectively recorded well-being.

Method Job strain hypothesis was tested among 267 health care employees from a two-wave Dutch panel survey with a 2-year time lag.

Results Significant demand/control interactions were found for mental and emotional demands, but not for physical demands. The association between job demands and job satisfaction was positive in case of high job control, whereas this association was negative in case of low job control. In addition, the relation between job demands and
\end{abstract}

\section{J. de Jonge $(\square)$}

Human Performance Management Group,

Department of Industrial Engineering and Innovation Sciences, Eindhoven University of Technology,

P.O. Box 513, 5600 MB Eindhoven, The Netherlands

e-mail: j.d.jonge@tue.nl

N. van Vegchel $\cdot$ W. Schaufeli

Department of Social and Organizational Psychology,

Utrecht University,

Utrecht, The Netherlands

\section{A. Shimazu}

Department of Mental Health, Graduate School of Medicine, University of Tokyo,

Tokyo, Japan

\section{Dormann}

Department of Work, Organizational and Economic Psychology, Institute of Psychology, Johannes Gutenberg University, Mainz, Germany psychosomatic health symptoms/sickness absence was negative in case of high job control and positive in case of low control.

Conclusion Longitudinal support was found for the core assumption of the DC model with specific measures of job demands and job control as well as self-report and objectively recorded well-being.

Keywords Demand-control model · Multidimensionality . Emotional demands · Decision authority · Sickness absence · Panel survey

\section{Introduction}

Undoubtedly one of the most widely cited work stress models is the demand-control (DC) model [1-3]. According to Karasek and Theorell [3], "elevation of risk with a demanding job appears only when these demands are in interaction with low control on the job" (p9). As Wall and associates [4] have noted, this implies that job demands can increase with almost no threat to psychological strain as long as control at work is also enhanced. Hence, in predicting employee well-being, a crucial issue of the DC model is the interaction between two key constructs, namely job demands and decision latitude. Within the DC model, job demands refer to a task's mental workload and the mental arousal needed to carry out the task [3]. Decision latitude is a composite measure of the employee's autonomy to make decisions on the job (decision authority) and the breadth of skills used by the employee on the job (skill discretion; [5]). The DC model has two distinct hypotheses accordingly. The first (strain) hypothesis maintains that a combination of high demands and low decision latitude leads to job strain (such as exhaustion and psychosomatic 
health complaints). The second (active learning) hypothesis predicts that a combination of both high demands and high decision latitude will increase work motivation, learning, and personal growth.

Although an overwhelming number of empirical studies that include the DC model have been conducted over the past decades, only a relatively small number of studies have shown support for the core assumption that particularly the interaction of demands and decision latitude leads to an elevated risk of strain (for overviews, see [6-9]). For instance, in a review by Van der Doef and Maes $[8,9]$ it was found that 30 out of 78 studies showed (partial) support for interaction effects (success rate of 38\%). Several authors have argued that the probability of finding significant interaction effects might be affected by the conceptualization and operationalization of the two key concepts of the model $[4,10,11]$. For instance, Söderfeldt and colleagues [12] as well as Kristensen and associates [13] demonstrated the importance of including emotional demands in the DC model. In addition, Wall et al. [4] detected interaction effects for a more focused control measure and job demands in relation to job satisfaction, whereas they could not demonstrate such an effect when a broader control measure (i.e., decision latitude) was included in parallel analyses. An important feature of these studies seems to be the specificity with which demands and control were measured. In fact, the reviews by Van der Doef and Maes [8,9] showed that supportive studies of interactions were more likely to measure specific demands (e.g., time pressure) combined with a corresponding aspect of control (such as decision authority over pace and method). So, Cooper, Dewe, and O'Driscoll [14] concluded that "Evidence to date shows some support for the Karasek model, particularly when salient job demands and areas of control are clearly defined and are matched with each other." (p140).

A related issue of finding significant interaction effects might be affected by the research design used. For instance, Van der Doef and Maes [8,9] noted that hardly any longitudinal study included in their review supported the demand/control interaction. In addition, De Lange and colleagues [15] reviewed 45 longitudinal demand/control studies and noted only modest support for the DC model. Therefore, it seems more difficult to demonstrate demand/ control interaction effects in longitudinal studies compared to cross-sectional studies. However, it should be noted that the total number of longitudinal studies is rather limited, which precludes firm conclusions in this respect.

Finally, Frese and Zapf [16] have argued that asking the respondent to indicate the stressfulness of a situation might enlarge the mental and/or emotional processing that the item requires, elevating the risk for method variance between self-report predictors and outcomes (see also
[17]). To minimize bias, they suggested to use more objective indicators as well, such as behavioral or physiological outcomes. Several review studies have confirmed that behavioral outcomes such as sickness absence have only rarely been considered in testing the DC model (e.g., [15]). For that very reason, we will use objectively recorded sickness absence data as well.

So, the present study will expand earlier DC studies with [1] more specific measures of demands and control, [2] a longitudinal design, and [3] a mixture of self-report and objectively recorded outcomes.

\section{Specific Job Demands and Control}

Over the past decades, the nature of job demands has changed considerably as a consequence of the changing nature of work (cf., [18]). For instance, there has been a shift from physical demands to mental demands (e.g., [19]) as well as from physical demands to emotional demands (e.g., [20]). That is not to say that physical demands have disappeared, as they still remain important in certain professions. But the increased use of technology and an increase in service jobs with direct client or customer contact has led to more mental and emotional demands. It is important to distinguish between these three types of job demands as they influence different aspects of human functioning [21]. Firstly, physical demands affect the musculo-skeletal system because of the execution of physical activities (e.g., carrying and lifting). Secondly, mental demands primarily involve information processing, such as memory and planning. And finally, emotional demands have an impact on feelings and emotions and are strongly related to interpersonal relationships (e.g., caring and concern for others).

Although literature on the DC model equates job decision latitude with job control, the operationalization of decision latitude shows clear differences (e.g., [4]). The measure of decision latitude includes not only items referring to job control, but also items tapping skill level, variety, creativity, and learning new things (e.g., "My job requires me to be creative," "My job requires a high level of skill"). Karasek [5] acknowledged this issue by stating that decision latitude is composed of two more specific, theoretically distinguishable concepts: decision authority and skill discretion.

Empirical studies have indicated the importance of differentiating between decision authority and skill discretion. For instance, in multiple independent samples, Smith and colleagues [22] showed that decision latitude loaded on two separate factors, reflecting decision authority and skill discretion. In a similar vein, several studies showed that a correlated three-factor model (i.e., job demands, decision 
authority, and skill discretion) fitted the data better than a two-factor model, consisting of job demands and decision latitude [23, 24]. Furthermore, studies that separately analyzed decision authority and skill discretion reported different and sometimes even opposite effects of decision authority versus skill discretion on outcome measures (e.g., [24-26]). For example, a heterogeneous study among 1,739 employees showed that decision authority was negatively associated with psychosomatic health complaints and sickness absence, whereas skill discretion was positively associated with those outcomes [25]. So, it has been argued that a high level of skill discretion could be perceived as a demand rather than a protective factor. Taken together, empirical evidence supports the proposition that decision authority and skill discretion are related but distinct concepts.

\section{The Present Study}

Given limitations of existing DC studies (i.e., crosssectional, global measures, self-report), the present study tested the DC model with a longitudinal design, and included specific measures of job demands (i.e., mental, emotional, and physical demands) and a specific measure of job control (i.e., decision authority) in relation to employee well-being. Three types of outcome variables (both selfreport and objectively registered data) were used to represent employee well-being, namely psychological (i.e., job satisfaction), physical (i.e., psychosomatic health complaints), and behavioral (i.e., sickness absence) outcomes (cf., [27]). We tested the following hypothesis:

Hypothesis Job control (Time 1) moderates the effect of job demands (Time 1) on poor well-being (Time 2). There is a stronger association between job demands and poor wellbeing for employees with low job control than for employees with high job control.

\section{Method}

Procedure and Participants

A two-wave panel survey was conducted among employees of a Dutch care foundation, including different nursing homes for the elderly. All employees were invited to participate on a voluntary basis. All questionnaires contained administration numbers for second round identification. For reasons of confidentiality, the code to these numbers was only known to the researchers, and questionnaires could be returned in sealed envelopes. This selfreport questionnaire was distributed on two occasions in the same month with a 2-year time interval. In this way possible seasonal fluctuations were controlled for. Moreover, Dormann and Zapf [28] showed that a time interval of 2 years is most appropriate to demonstrate effects of job characteristics on employee well-being. At Time 1, 554 employees received a questionnaire, 405 of which returned the questionnaire (response rate $73 \%$ ). At Time 2, 420 out of 624 filled out the questionnaire ( $67 \%$ response rate). The final panel consisted of 267 persons ( $48 \%$ of the initial group) who responded to the questionnaire on both occasions.

The demographic characteristics of the respondents in the final panel showed that the ages ranged from 18 to 64 years $(M=41.0, \mathrm{SD}=8.7)$. Most respondents were female $(91.4 \%)$. The mean tenure time was 11.3 years $(\mathrm{SD}=7.5)$. Respondents worked $23.9 \mathrm{~h}$ a week $(\mathrm{SD}=8.7)$ on average, and $45.9 \%$ worked regular hours and $54.1 \%$ variable hours. The most common job category of respondents was nurse or nurses' aide $(62.9 \%)$. The remaining respondents were active in administration (15.7\%), medical services (9.0\%), management (4.5\%), and other occupations (7.9\%).

To check whether non-response due to attrition (or dropout) might have influenced the results, $t$ tests were calculated to compare the panel group (at Time 1) with the respondents who only responded at Time 1 (i.e., the dropouts). No significant differences were found for the demographic variables. For the other variables, significant differences appeared between the panel group and the dropouts for mental demands and frequency index only (i.e., the panel group scored more positively on these two variables than the dropouts). Calculation of Cohen's $d$ [29] however indicated that the size of these effects can be characterized as small. Therefore, we believe that these biases did not influence the results severely.

\section{Measures}

Mental demands were measured with an 8-item scale [30]. The scale measured both qualitative and quantitative mentally demanding aspects of the job, such as working under time pressure, working hard, strenuous work, and job complexity. An example item is: "In the unit were I work, work is carried out under time pressure." Coefficient alpha was 0.90 at Time 1 and 0.89 at Time 2.

Emotional demands were assessed with a 12 -item scale with items about emotional demanding aspects of work, being confronted with emotionally demanding behavioral characteristics of clients (e.g., awkward or aggressive clients) and traumatic events such as human suffering and dying [31]. An example is: "In my work, I am confronted with sickness or other human suffering." Coefficient alpha was 0.86 at Time 1 and 0.85 at Time 2 . 
Physical demands were measured by a 7-item scale, containing items about carrying heavy loads, restricted standing, severe bending, and carrying at shoulder height [30]. For instance, "In my work I have to carry at shoulder height for a long time." Coefficient alpha was 0.91 at Time 1 and 0.90 at Time 2.

All three demand measures have a 5-point response category ranging from 1 (never) to 5 (always).

Job Control A Dutch translation of Karasek's job content questionnaire [23] was used to measure the specific control construct of the DC model, termed decision authority. Decision authority was measured with three items concerning freedom to make decisions on the job that relate to work content and ways of production. An example item is: "My job allows me to make a lot of decisions on my own." The response categories ranged from 1 (strongly agree) to 4 (strongly disagree) and were reverse-coded afterwards. Coefficient alpha was 0.70 at Time 1 and 0.68 at Time 2.

Job satisfaction was measured with a single item, namely: "I am satisfied with my current job." The response scale ranged from 1 (strongly disagree) to 5 (fully agree). According to Wanous, Reichers, and Hudy [32], a reliability of at least 0.57 can be assumed for this singleitem measure. In addition, they have shown that this single item correlated highly with multi-item scales. Therefore, this single global item of satisfaction seems to offer a valid and economical measure.

Psychosomatic health complaints were assessed with a 13-item scale [33]. Respondents were asked to indicate whether they had been troubled by particular health complaints (such as headache, stomach problems, or dizziness) during the past 6 months $(1=$ yes, $0=$ no). Reliability assessed by KR-20 was 0.85 at Time 1 and 0.78 at Time 2 .

Sickness absence was registered by the personnel administration of the organization, and could be considered an objectively recorded measure (i.e., independent of employees' assessment). We used the frequency index, which consisted of the number of separate incidents of sickness absence in one full calendar year, regardless of the duration.

Control Variables Age, gender, and education were included as control variables, as those variables are known for their possibly confounding influence on the relation between work variables and employee well-being.

\section{Analytical Procedure}

First, descriptive analyses were conducted to obtain an initial overview of the data. Second, stepwise multiple regression analyses (MRAs) were used to examine the causal relation between job characteristics and employee well-being. The MRAs were conducted with simultaneous entry of variables within each hierarchical step. In Step 1, the Time 1 control variables were entered (i.e., gender, age, and education). In Step 2, the dependent variable at Time 1 was entered. In step 3, we added two independent variables; that is, one specific job demand and job control (both measured at Time 1). Finally, in Step 4 the interaction term representing the interaction between a specific job demand and job control was entered (i.e., demand $\times$ control). With the help of an incremental $F$ test $\left(F_{\text {inc }} ;[33]\right)$, we tested whether the interaction term (Step 4) yielded a significant increment in explained variance over and above the variance explained by the additive effects of the independent variables (Step 3). One problem of this analytical approach is the lack of power [34]. Therefore, we used a more liberal significance criterion of 0.10 for our hypothesis (cf., [35]). The multiplicative interaction term was computed from centered job characteristics (i.e., mean subtraction) to reduce problems of multicollinearity [36]. Accordingly, unstandardized regression coefficients are presented in the table $[34,36]$.

\section{Results}

First of all, the means, standard deviations, test-retest reliabilities, and Pearson correlations were calculated (see Table 1). Test-retest reliabilities ranged from 0.39 to 0.77 . Table 1 also shows that the specific demand measures (i.e., mental, emotional, and physical demands) were moderately correlated. In all cases, the measures were correlated at lower levels than their respective scale reliabilities. According to Sargent and Terry [37], this suggests that empirically distinct, yet related constructs are being assessed. All correlations between Time 1 job characteristics and Time 2 well-being outcomes were in the expected direction, although they were not all significant.

To test the influence of Time 1 job characteristics on Time 2 employee well-being, a series of stepwise multiple regression analyses was conducted. For each outcome variable, separate analyses tested the significance of each set of multiplicative interaction terms. Accordingly, each column in Table 2 shows the results of a different combination of job demands (i.e., mental, emotional, or physical demands) and job control (i.e., decision authority) in the respective multiplicative interaction term.

Table 2 shows results of the analyses of demands and control at Time 1 in relation to job satisfaction at Time 2 . The combination of mental demands and job control yielded a significant interaction effect, as did the combination of emotional demands and job control. This means that 


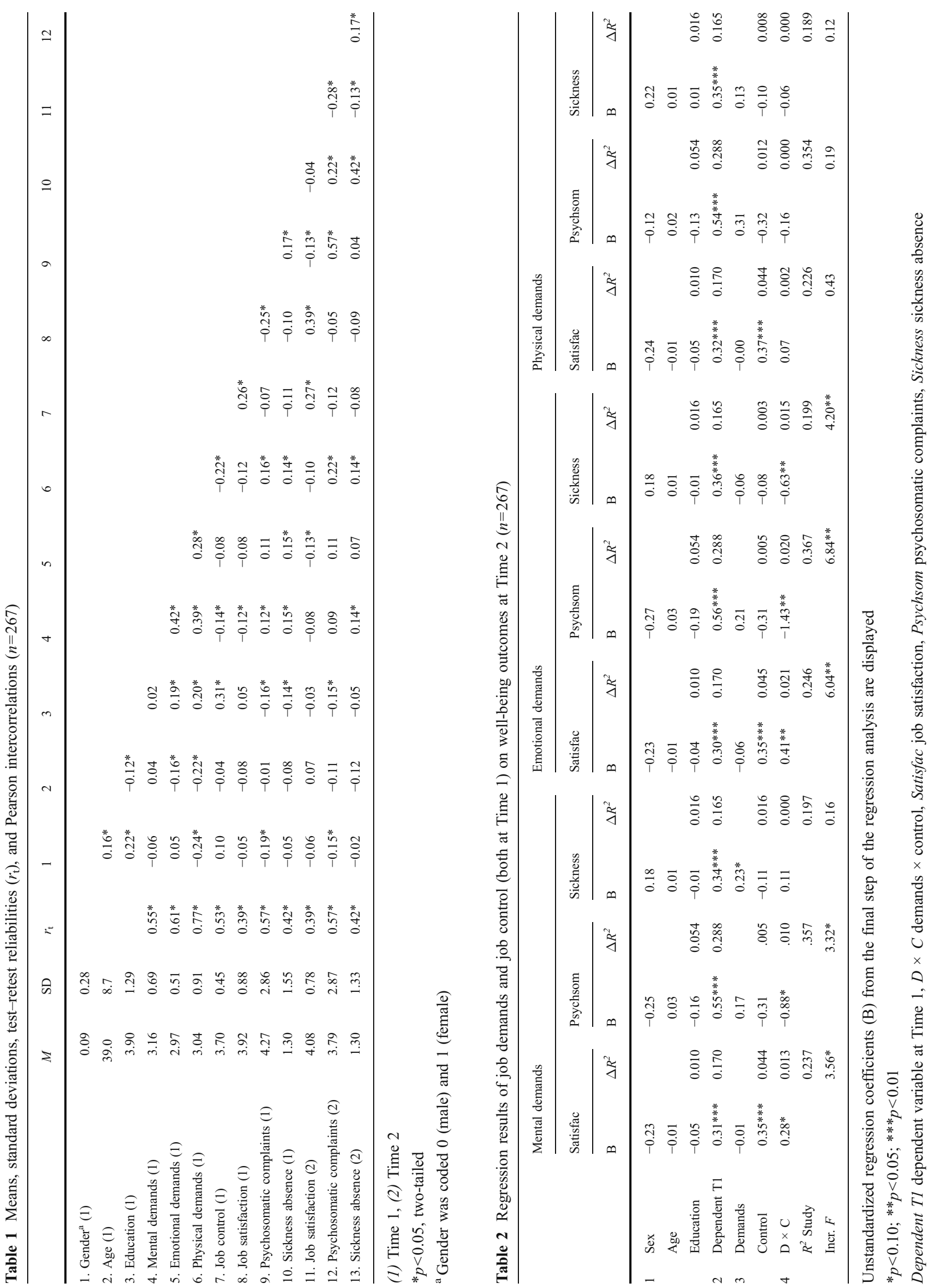


additional variance was explained, over and above the main effects, by the interaction terms (as shown by the incremental $F$ test). The combination of physical demands and job control did not result in a significant interaction.

To examine the nature of the significant multiplicative interaction terms, they were graphically displayed according to the method proposed by Aiken and West [34]. Values of the predictor variables were represented at one standard deviation below and one standard deviation above the mean. Regression lines were then estimated by entering these values in the regression equation. Figures 1 and 2 show graphical representations of the interactions between demands and job control at Time 1 observed for job satisfaction at Time 2. These figures show that negative effects of high job demands (+1 SD) on job satisfaction are dependent on the amount of job control. That is, if the employee experienced a high amount of control (+1 SD), the employee remained as happy with his/her job or would even be slightly more satisfied with his/her work 2 years later. On the other hand, for employees who reported a low amount of control ( $-1 \mathrm{SD})$, job satisfaction decreased over time (as could be expected). Main effects may be interpreted in terms of the average effect of a predictor across values of a moderator. This average effect usually will be a meaningful piece of information as well (cf., [36]). As far as the main effects are concerned, findings showed that only the amount of job control was positively associated with job satisfaction.

The analyses with regard to psychosomatic health complaints at Time 2 are presented in Table 2, too. One significant multiplicative interaction was observed for mental demands and job control, and one for emotional demands and job control. For physical demands, no significant interaction effects were found.

Figures 3 and 4 show the multiplicative interactions for psychosomatic health complaints. These figures show that employees who initially reported high job demands

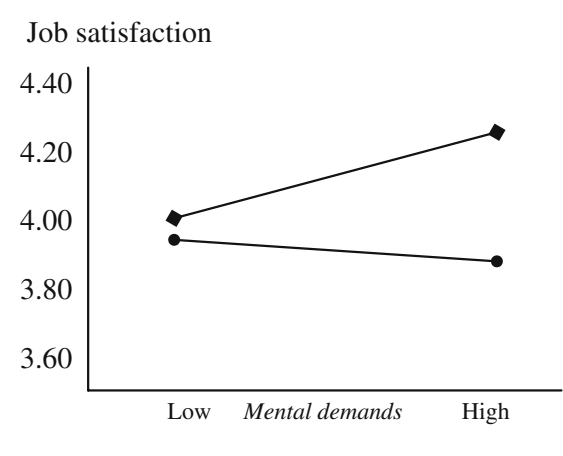

$\diamond$ High decision authority $\bullet$ Low decision authority

Fig. 1 Interaction between mental demands and job control (decision authority) for job satisfaction. Filled diamond indicates high decision authority; filled circle indicates low decision authority

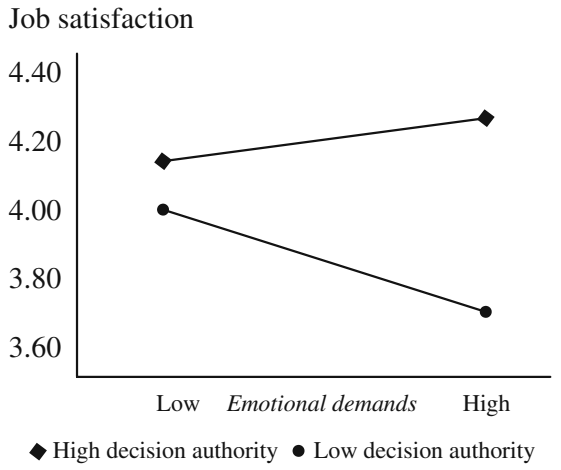

Fig. 2 Interaction between emotional demands and job control (decision authority) for job satisfaction. Filled diamond indicates high decision authority; filled circle indicates low decision authority

accompanied by high levels of job control experienced fewer psychosomatic health complaints 2 years later. However, if employees do have low control at work, high job demands will lead to more psychosomatic health complaints over time. In all cases, employees with high demands and low control reported the most psychosomatic health complaints 2 years later. Thus, the pattern of interactions for psychosomatic health complaints was largely similar to the patterns for job satisfaction.

The results for the frequency index of sickness absence are also presented in Table 2. A significant multiplicative interaction was found only for emotional demands and job control. This interaction is visually displayed in Fig. 5. The pattern was similar to that found for psychosomatic health complaints. That is, the influence of high emotional demands on sickness absence 2 years later depended on the amount of job control available to the employee. If a high level of control was available, the employee called in sick less frequently 2 years later, whereas employees with a low level of control were more often absent from work due to sickness 2 years later. Finally, main effect results indicated that only mental demands were positively associated with sickness absence.

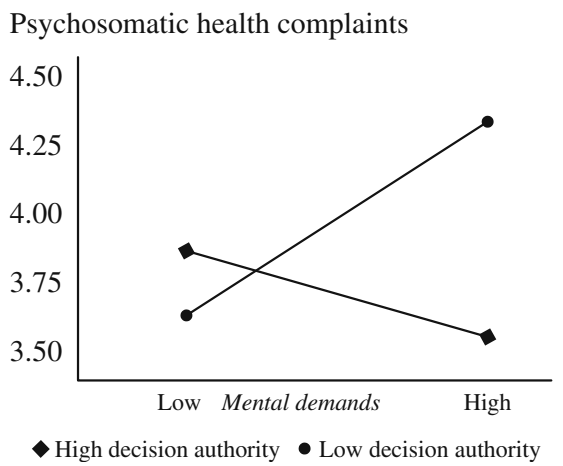

Fig. 3 Interaction between mental demands and job control (decision authority) for psychosomatic health complaints. Filled diamond indicates high decision authority; filled circle indicates low decision authority 
Psychosomatic health complaints

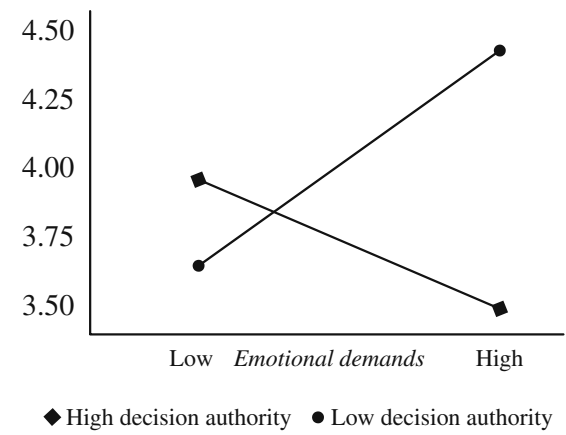

Fig. 4 Interaction between emotional demands and job control (decision authority) for psychosomatic health complaints. Filled diamond indicates high decision authority; filled circle indicates low decision authority

\section{Discussion}

The present study introduced some theoretical refinements of the DC model and tested them longitudinally within a sample of health care employees. In general, longitudinal support was found for the core assumption of the DC model; that is, job control moderated the effects of job demands on subsequent poor well-being 2 years later. More specifically, two out of three interactions turned out to be significant for both job satisfaction and psychosomatic health complaints (about 67\%), whereas one out of three interactions was found for sickness absence (about 33\%). Furthermore, significant interactions were detected for mental and emotional demands and not for physical demands. Finally, it should be noted that all significant interactions were in the expected direction. Generally, the association between job demands and job satisfaction was positive in the case of high job control, whereas this association was negative in the case of low job control. In a similar vein, the relation between job demands and psychosomatic symptoms/sickness absence was negative in case of high job control and positive in case of low control.

Several authors have argued that the inconsistent evidence for demand-control interactions may be attributable to the use of (overly) general scales, encompassing different aspects rather than more specific measures (e.g., [4, 38, 39]). The combination of emotional demands and job control seemed to be most effective in the prediction of job satisfaction, psychosomatic health complaints, and sickness absence frequency 2 years later. Several authors claim that job stress is all about emotions; many job demands elicit emotional processes (cf., [40, 41]). From this perspective, we might assume that demands that are assessed on an emotional level will show strong interaction effects, as they are not mediated by emotions, compared to job demands that are measured on a mental or physical level. This may explain why interactions including emotional demands were most frequently reported in the prediction of employee well-being (e.g., [12, 30, 31, 42]).

Of course, the occupation under study, in our case health care employees, also determines which particular demands are important or frequently experienced. Although many researchers agree that excessive emotional demands are responsible for the development of burnout and psychosomatic health complaints, most studies have not directly measured this kind of demands (e.g., [43]). It is only recently that researchers have started measuring emotional demands within job stress research (e.g., [13, 30, 42]).

Furthermore, the specific mental demand concept yielded two significant interactions with job control (i.e., decision authority). An explanation for this might be that both mental demands and decision authority can be regarded as job characteristics that merely involve cognitive processes (e.g., [38]). Therefore, from a functional selfregulation perspective, decision authority could be viewed as more functional for mental demands than for physical demands, and it is more likely to buffer the negative effects of job demands when both are measured on the same level (cf. matching principle, [44, 45]). In recent work by Magnuson Hanson, Theorell, Oxenstierna, Hyde, and Westerlund [46], decision authority had been used as the only representative of job control. Among other things, their prospective study showed that high mental demands and low decision authority were important predictors of adverse health symptoms as well.

Finally, though we had assumed that physical demands should be important for health care employees due to the many physical activities that have to be performed (such as carrying and lifting), no interactions were found. This is in line with a number of studies which showed that the particular interaction between physical demands and control in relation to employee well-being failed to reach statistical significance [30, 47]. In addition, Hollmann and

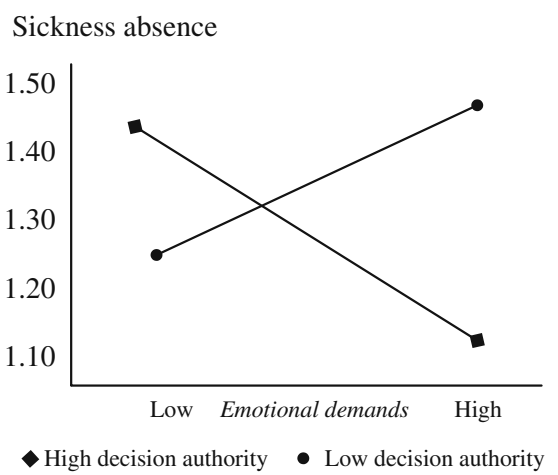

Fig. 5 Interaction between emotional demands and job control (decision authority) for sickness absence (frequency index). Filled diamond indicates high decision authority; filled circle indicates low decision authority 
colleagues [48] only found a positive effect of job control under conditions of low physical work load, but not for physically demanding activities. An explanation for this might be that decision authority is not an appropriate resource to compensate for the negative effects of physical demands. Indeed, a study among health care employees showed that it is physical resources rather than job control which were important to counteract physical demands [45].

Because we used both subjective and objective outcome measures, we had an opportunity to compare their respective relations with job characteristics as well as the amount of explained variance. First, the sign of relations between DC variables and both types of outcomes were similar in all but one case. Second, excluding the effect of the T1 outcome, the amount of explained variance $\left(R^{2}\right)$ was 2.4$3.4 \%$ in case of sickness absence, whereas $R^{2}$ was $5.6-$ $7.9 \%$ in case of the subjective outcome variables. This is consistent with other studies on objectively recorded sickness absence (e.g., [49]). A possible explanation is that the results have been partly contaminated by common method variance (e.g., [16]). Another explanation may be that sickness absence has a multifactorial etiology: different factors are related to absence from work, not only the core job characteristics of the DC model [25].

The present study has some strengths and some limitations. First, obvious strengths of our study are the use of a longitudinal design and objectively recorded outcome data, which minimizes method bias to some extent. However, our data were collected in discrete time samples while the processes to be observed are continuous. Therefore, we cannot obtain valid parameter estimates until the measurement period matches the causal lag [16]. So, a suggestion for future research is to conduct more longitudinal multi-wave studies with different time lags [28]. Second, our study population contains employees of a single industry (nursing homes) only, and mostly females. However, gender differences appeared not to be an issue in this study (see also the non-significant regression coefficients in Table 2). To generalize the results to other occupations, more research in other and larger occupational groups is needed.

Several practical implications can be derived from the findings as well. The results indicate that specific job demands and job control influenced the state of employee well-being 2 years later. So, work-related interventions aimed at decreasing specific job demands and particularly increasing job control may indeed improve employee wellbeing in the longer run. In addition, using more specific measures provided insight into the specific types of demands and resources that may be particularly important for employee well-being. For instance, the present study has demonstrated that both emotional and mental demands as well as decision authority are important predictors of employee well-being. Changing these job characteristics through job redesign would seem to be an effective tool for enhancing employee well-being (and decreasing absenteeism). This is in line with legal acts and guidelines that are aimed at improving and/or maintaining a healthy psychosocial work environment.

To conclude, the present longitudinal study has shown the need of including more specific measures of demands and control into the DC model. Multidimensional measures allow researchers to gear their measures on the occupation under study (see also [50]). Therefore, we believe that these results do have both theoretical and practical value, as they have shown interaction effects in relation to self-reported as well as objectively recorded well-being when specific measures were used to represent job demands and job control. In this perspective, Theorell [51] noted that critical analyses, as well as ideas for continued research, improvements in measures, and model building are important for those people who find that the world of work is a moving target.

Acknowledgements This work has been supported by grants from NWO, the Dutch Organisation for Scientific Research (Grant 580-02209), and the Japan Society for the Promotion of Science (Grant S-09118).

Open Access This article is distributed under the terms of the Creative Commons Attribution Noncommercial License which permits any noncommercial use, distribution, and reproduction in any medium, provided the original author(s) and source are credited.

\section{References}

1. Karasek Jr RA. Job demands, job decision latitude, and mental strain: implications for job redesign. Adm Sci Q. 1979;24:285-308.

2. Karasek R. Low social control and physiological deregulationthe stress-disequilibrium theory, towards a new demand-control model. Scand J Work Environ Health. 2008;Suppl 6:S117-35.

3. Karasek RA, Theorell T. Healthy work: stress, productivity and the reconstruction of working life. New York: Basic Books; 1990.

4. Wall TB, Jackson PR, Mullarkey S, Parker SK. The demandscontrol model of job strain: a more specific test. J Occup Organ Psychol. 1996;69:153-66.

5. Karasek R. Control in the workplace and its health-related aspects. In: Sauter SL, Hurrell JJ, Cooper CL, editors. Job control and worker health. Chichester: Wiley; 1989. p. 129-59.

6. Belkiç K, Landsbergis P, Schnall P, Baker D, Theorell T, Siegrist J, et al. Psychosocial factors: review of empirical data among men. In: Schnall PL, Belkiç K, Landsbergis P, Baker D, editors. The workplace and cardiovascular disease. Philadelphia: Hanley \& Belfus; 2000. p. 24-6.

7. Bongers P, Kremer A, Laak J. Are psychosocial factors, risk factors for symptoms and signs of the shoulder, elbow, or hand/ wrist? A review of the epidemiological literature. Am J Ind Med. 2002;41:315-42.

8. van der Doef M, Maes S. The job demand-control(-support) model and physical health outcomes: a review of the strain and buffer hypotheses. Psychol Health. 1998;13:909-36.

9. van der Doef M, Maes S. The job demand-control(-support) model and psychological well-being: a review of 20 years of empirical research. Work Stress. 1999;13:87-114. 
10. de Jonge J, Kompier MAJ. A critical examination of the demandcontrol-support model from a work psychological perspective. Int J Stress Manag. 1997;4:253-8.

11. van Vegchel N, de Jonge J, Landsbergis PA. Occupational stress in (inter)action: the interplay between job demands and job resources. J Organ Behav. 2005;26:535-60.

12. Söderfeldt B, Söderfeldt M, Jones K, O'Campo P, Muntaner C, Ohlson C-G, et al. Does organization matter? A multilevel analysis of the demand-control model applied to human services. Soc Sci Med. 1997;44:527-34.

13. Kristensen TS, Hannerz H, Høgh A, Borg V. The Copenhagen psychosocial questionnaire - a tool for the assessment and improvement of the psychosocial work environment. Scand J Work Environ Health. 2005;31:438-49.

14. Cooper CL, Dewe PJ, O'Driscoll MP. Organizational stress: a review and critique of theory, research, and applications. Thousand Oaks: Sage; 2001.

15. de Lange AH, Taris TW, Kompier MAJ, Houtman ILD, Bongers PM. "The very best of the millennium": longitudinal research and the demand-control-(support) model. J Occup Health Psychol. 2003;8:282-305.

16. Frese M, Zapf D. Methodological issues in the study of work stress: objective versus subjective measurement of work stress and the question of longitudinal studies. In: Cooper CL, Pain R, editors. Causes, coping and consequences of stress at work. Chichester: Wiley and Sons; 1988. p. 375-411.

17. Kivimäki M, Vahtera J, Elovainio M, Keltikangas-Järvinen L, Virtanen $M$, Hintsanen $M$, et al. What are the next steps for research on work stress and coronary heart disease? Scand J Work Environ Health. 2008;Suppl 6:S33-40.

18. Johnson JV. Globalization, workers' power and the psychosocial work environment - is the demand-control-support model still useful in a neoliberal era? Scand J Work Environ Health. 2008; Suppl 6:S15-21.

19. Siegrist J. Effort-reward imbalance and health in a globalized economy. Scand J Work Environ Health. 2008;Suppl 6:S163-68.

20. Dormann C, Zapf D. Customer-related social stressors and burnout. J Occup Health Psychol. 2004;9:61-82.

21. Hockey GRJ. Work environments and performance. In: Chmiel N, editor. Introduction to work and organizational psychology: a European perspective. Malden: Blackwell Publishers Inc; 2000. p. 206-30.

22. Smith CS, Tisak J, Hahn SE, Schmieder RA. The measurement of job control. J Organ Behav. 1997;18:225-37.

23. Karasek RA, Brisson C, Kawakami N, Houtman I, Bongers P, Amick B. The job content questionnaire (JCQ): an instrument for internationally comparative assessments of psychosocial job characteristics. J Occup Health Psychol. 1998;3:322-55.

24. Schreurs PJG, Taris TW. Construct validity of the demand-control model: a double cross-validation approach. Work Stress. 1998;12: 66-84.

25. de Jonge J, Reuvers MMEN, Houtman ILD, Bongers PM, Kompier MAJ. Linear and nonlinear relations between psychosocial job characteristics, subjective outcomes, and sickness absence: baseline results from SMASH. J Occup Health Psychol. 2000;5:256-68.

26. Rafferty Y, Friend R, Landsbergis PA. The association between job skill discretion, decision latitude and burnout. Work Stress. 2001;15:73-85.

27. Kahn RL, Byosiere P. Stress in organizations. In: Hough LM, editor. Handbook of industrial and organizational psychology, vol. 3. 2nd ed. Palo Alto: Consulting Psychologists Press; 1992. p. 571-650.

28. Dormann C, Zapf D. Social stressors at work, irritation, and depressive symptoms: accounting for unmeasured third variables in a multi-wave study. J Occup Organ Psychol. 2002;75:33-58.

29. Goodwin CJ. Research in psychology: methods and design. 3rd ed. New York: John Wiley \& Sons; 2003.
30. de Jonge J, Mulder MJGP, Nijhuis FJN. The incorporation of different demand concepts in the demand-control model: effects on health care professionals. Soc Sci Med. 1999;48:1149-60.

31. van Vegchel N, de Jonge J, Meijer T, Hamers JPH. Different effort constructs and effort-reward imbalance: effects on employee wellbeing in ancillary health care workers. J Adv Nurs. 2001;34:128-36.

32. Wanous JP, Reichers AE, Hudy MJ. Overall job satisfaction: how good are single-item measures? J Appl Psychol. 1997;82:247-52.

33. Jansen ME, Sikkel D. Verkorte versie van de VOEG-schaal [Short version of the VOEG-scale]. Gedrag Samenl. 1981;2:78-82.

34. Aiken LS, West SG. Multiple regression: testing and interpreting interactions. Newbury Park: Sage; 1991.

35. Frese M. Social support as a moderator of the relationship between work stressors and psychological dysfunctioning: a longitudinal study with objective measures. J Occup Health Psychol. 1999;4:179-92.

36. Jaccard J, Turrisi R, Wan CK. Interaction effects in multiple regression. Newbury Park: Sage; 1990. Series on Quantitative Applications in the Social Sciences.

37. Sargent LD, Terry DJ. The effects of work control and job demands on employee adjustment and work performance. J Occup Organ Psychol. 1998;71:219-36.

38. de Jonge J, Dormann C. The DISC model: demand-induced strain compensation mechanisms in job stress. In: Dollard MF, Winefield HR, Winefield AH, editors. Occupational stress in the service professions. London: Taylor \& Francis; 2003. p. 43-74.

39. Terry DJ, Jimmieson NL. Work control and employee well-being: a decade review. In: Cooper CL, Robertson IT, editors. International review of industrial and organizational psychology, vol. 14. Chichester: Wiley; 1999. p. 95-148.

40. Gaillard AWK, Wientjes CJE. Mental load and work stress as two types of energy mobilization. Work Stress. 1994;8:141-52.

41. Lazarus RS. Stress and emotion: a new synthesis. London: Free Association Books; 1999.

42. de Jonge J, Le Blanc PM, Peeters MCW, Noordam H. Emotional job demands and the role of matching job resources: a crosssectional survey study among health care workers. Int J Nurs Stud. 2008;45:1460-9.

43. Zapf D. Emotion work and psychological well-being: a review of the literature and some conceptual considerations. Hum Res Manage Rev. 2002;12:237-68.

44. Cohen S, Wills TA. Stress, social support, and the buffering hypothesis. Psychol Bull. 1985;98:310-57.

45. de Jonge J, Dormann C. Stressors, resources, and strain at work: a longitudinal test of the triple-match principle. J Appl Psychol. 2006;91:1359-74.

46. Magnusson Hanson LL, Theorell T, Oxenstierna G, Hyde M, Westerlund $\mathrm{H}$. Demand, control and social climate as predictors of emotional exhaustion symptoms in working Swedish men and women. Scand J Work Environ Health. 2008;36: 737-43.

47. de Jonge J, Dollard MF, Dormann C, Le Blanc PM, Houtman ILD. The job demand-control model: specific demands, specific control, and well-defined groups. Int J Stress Manag. 2000;7:269-87.

48. Hollmann S, Heuer H, Schmidt KH. Control at work: a generalized resource factor for the prevention of musculoskeletal symptoms? Work Stress. 2001;15:29-39.

49. Vathera J, Pentti J, Uutela A. The effect of objective job demands on registered sickness absence spells; do personal, social and job-related resources act as moderators? Work Stress. 1996;10:286-308.

50. Choi B, Kawakami N, Chang S, Sangbaek K, Bjorner J, Punnett $\mathrm{L}$, et al. A cross-national study on the multidimensional characteristics of the five-item psychological demands scale of the Job Content Questionnaire. Int J Behav Med. 2008;15:120-32.

51. Theorell T. Introduction. Scand J Work Environ Health. 2008; Suppl 6:S3-5. 